* Corresponding author

Phone +421556023524

E-mail address: lubos.kascak@tuke.sk

(Luboš Kaščák, Ing. PhD.)

Article information

Article history: AMS-Volume15-No.4-00126-11

Received 23 March 2011

Accepted 26 May 2011

\section{Influence of Corrosive Environment on the Surface Quality of Spot Welds}

\author{
Emil Spišák, Luboš Kaščák*, Janette Brezinová, Ján Viňáš, Dagmar Draganovská, \\ Daniel Jankura
}

Department of Technologies and Materials, Faculty of Mechanical Engineering, Mäsiarska 74, 04201 Košice, Slovak Republic

\section{BIOGRAPHICAL NOTES}

Emil Spišák, prof. Ing. CSc. (born 1955) is professor of Department of Technologies and Materials, Faculty of Mechanical Engineering, Technical University of Košice. He is head of the Department of Technologies and Materials and Vice-Rector for Development and Construction of the University. He served as Vice-Dean for 4 years and ViceRector for 8 years. He works in the area of evaluating of material properties, material failures, analysis and quantification of production factors influence in production of thin steel sheet stamping parts, modelling and simulation of technological processes, mainly forming processes. He is national secretary and a member of International Deep-Drawing Research Group. He is author of 5 monographs and more than 200 publications in journals and conference proceedings at Slovakia and abroad. His published works were cited 115 times. He has been worked on 60 grant projects, research tasks and 47 projects solved for industry.

Luboš Kaščák, Ing. PhD. is an assistant professor at the Department of Technology and materials. He was born in 1974. He received scientific degree PhD. in 2004 in the field of properties evaluation of joined deep drawn sheets. He is an author of more than 70 publications in journals and conference proceeding in Slovakia and abroad. He has worked on several grant projects and research tasks.

Janette Brezinová, assoc. prof. Ing. PhD. (1968) is currently associate professor and associate dean for education at the Technical University of Košice, Faculty of Mechanical Engineering, Department of Materials and Technology. She graduated in Welding and Surface Treatment (1991), obtained the Ph.D. in the field of degradation in abrasive blast cleaning at the Technical University of Košice in 2003 and in 2008 was habilitated in the field of Mechanical Engineering and Materials. In her research work she focuses on surface treatment and materials, degradation phenomena during abrasive blast cleaning and shot peening, corrosion of metals, corrosion protection of metals, evaluation of organic and inorganic coatings, renovation of worn surfaces. J. Brezinová is the member of Slovak Metal Science Society. She is the author of more than 100 scientific works presented in journals and in proceeding from many international scientific conferences.

Ján Viňáš, Ing. PhD. (1977) is currently assistant professor at the Technical University of Košice, Faculty of Mechanical Engineering, Department of Materials and Technology. He graduated in Welding and Surface Treatment (2000), obtained the Ph.D. in the field of study the possibility of lifespan extension of crane wheels by hard surfacing at the Technical University of Košice in 2004. In his research work he focuses on welding of various materials, study of weldability, application of welding in renovation processes, hard surfacing, brazing, evaluation of wear resistance and quality of welds, evaluation of thermal sprayed coatings. J. Viňáš is the member of Slovak Metal Science Society and Slovak Welding Society. He is certified European Welding Engineer (EWE) and In- 
ternational Welding Engineer (IWE) and Welding Technologist. He is the author of more than 100 scientific works presented in journals and on many international scientific conferences.

Dagmar Draganovská, Ing. PhD. (born 1963) is currently assistant professor at the Technical University of Košice, Faculty of Mechanical Engineering, Department of Technologies and Materials. He graduated in Welding and Surface Treatment (1985), obtained PhD. degree in 2005 in the field of blasted surface evaluation and research of characteristics of new surfaces. In her research work she focuses on blasting technology, coating creation and evaluation its properties, surface protection against corrosion, surface activity and evaluation of $2 \mathrm{D}$ and $3 \mathrm{D}$ characteristics of newly created surfaces. She is the author of more than 70 scientific works at journals and international scientific conferences, 2 textbooks and 1 monograph. She is a member of Slovak Society for Surface Treatment. She has been worked on many research or grant projects and projects for industry.

Daniel Jankura, doc. Ing. PhD. (born 1949) is currently associated professor of Department of Technologies and Materials, Faculty of Mechanical Engineering, Technical University of Košice. He is graduated on Faculty of Metallurgy, TU in Košice, where he obtained scientific degree PhD in the field Physical Metallurgy and limit states of materials, (1981). In 2001 was habilitated at the Faculty of Mechanical Engineering, TU Košice in the field of Mechanical Engineering processes and Materials. His research works are focuses on surface treatment of materials, formation and properties of ceramic coatings, tribological properties of metals, welding and weldability of metallic materials, renovation of worn surfaces. D. Jankura is the member of the Slovak Society for Surface Treatment. He is the author of more the 125 scientific works presented in journals and conference proceedings at Slovakia and abroad.

\section{KEY WORDS}

Resistance Spot Welding, Tensile Test, Microhardness, Corrosion Resistance

\section{ABSTRACT}

CThe paper deals with the evaluation of quality of resistance spot welds. Hot-dip galvanized steel sheets of DX54D+Z quality were used for experi- ments. Electrochemical properties of used materials were observed. Carrying capacities of spot resistance welds were measured before as well as after exposure in corrosive environment. The tensile test was used for evaluation of carrying capacities. The quality of spot welds was evaluated on the base of microhardness measurements results realized on the scratch patterns too.

\section{Introduction}

The car body consists of several materials which need to be joined together to form one unit, usually by welding. Due to combining various types of materials having different mechanical properties and chemical composition, specific demands on the weldability of particular types of materials must be taken into consideration to optimize welding parameters with the aim of eliminating defects in welded joints [1,2].

One of the important requirements for materials used for vehicles is their corrosion resistance, which leads to the increasing share of chassis $[3,4]$. However, this type of surface treatment causes considerable problems for joining metal chassis. Conventional methods such as MIG welding or resistance spot welding, as well as unconventional methods such as laser welding lead to evaporation of protective layers near weld due to the heat and loss of the corrosion resistance of the welded parts [3].

The aim of the contribution is to analyse quality of welds on galvanized sheets and their corrosive properties. Protective efficiency of zinc coatings for automobile sheets was evaluated, based on the determination of their electrochemical characteristics in passivated and non-passivated state, as well as their corrosion resistance in simulated corrosion environments.

\section{Materials and methods}

Following materials were used for experiments:

\section{1) sample $A: D X 54 D+Z$}

- sheet thickness $0.70 \mathrm{~mm}$; zinc coated $140 \mathrm{~g} \cdot \mathrm{m}^{-2}$

- surface treatment: non-passivated

- use: for exterior body panels for DACIA LOGAN roof

2) sample $B: D X 54 D+Z$

- sheet thickness: $0.70 \mathrm{~mm}$; zinc coated $140 \mathrm{~g} \cdot \mathrm{m}^{-2}$

- surface treatment: passivated $\mathrm{Cr} 3+$

- use: for exterior body panels for DACIA LOGAN - 


\section{doors}

Test samples were cut to size $90 \times 40 \mathrm{~mm}$ according to STN EN 051 122, length of lapping was 30 $\mathrm{mm}$. Spot welding was carried out on pneumatic spot-welder BPK 20 with welding electrodes $\mathrm{CuCr}$ with $5 \mathrm{~mm}$ diameter. Selection of the welding parameters was based on the recommendations of British Standard (BS 1140) for spot welding of coated sheets and knowledge of weld growth mechanism [5]. However, the correction of the parameters was necessary, for the specific spot-welder. Welding parameters were: contact force $\mathrm{Fz}=2.6$ $\mathrm{kN}$, welding time $\mathrm{t}=14$ periods, welding current 85 kA $[1,2]$. Tensile tests according to STN 051122 were used for the evaluation of mechanical properties of spot welds before and after the exposure to the corrosive environments. The test of spots and full penetration welded joints were carried out on a test machine TIRA-test 2300, (VEB TIW Rauenstein).

The samples for microhardness evaluation were prepared according to ISO 6507-1 and ISO 6507-2. Microhardness on the cross scratch patterns was measured according to STN EN 1043-2 for hardness evaluation of particular areas of the weld and its transient phases.

The tests were carried out on Shimadzu Bubo microhardness tester with indenter Vickers under a load of $0.01 \mathrm{kN}$. Intender load time was $10 \mathrm{~s}$.

The microhardness was measured on cross scratch patterns according to scheme in Fig. 1. Three measurements were carried out: in the base material, heat affected zone and weld metal in DX54D+Z.

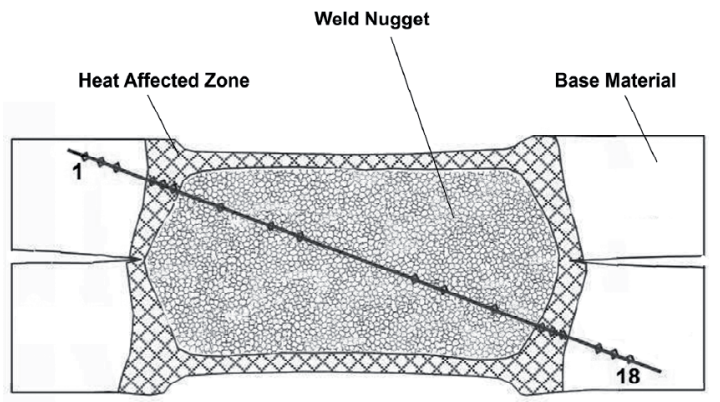

Fig. 1: Places of microhardness measurements.

Welds were exposed to salty environment of 5\% $\mathrm{NaCl}$ solution and ecological solution Solmag used during winter season on roads. The above environments simulated conditions of vehicle operation
$[6,7]$. Gravimetric method was used For the evaluation of the corrosion processes. Potentiodynamic polarization curves were measured for determination of the electrochemical characteristics of these materials. The values of Ek - corrosion potential by Tafel, Ik - corrosion current density and Rp - polarization resistance were measured. Electrochemical characteristics of the tested samples were evaluated before exposure to the corrosive environment and after 240, 480 and 720 hrs of exposure according to Tafel and Stern method. A computercontrolled potentiostat/galvanostat VOLTALAB 21 PGP201 (producer Radiometer Analytical, Denmark) with software VOLTAMASTER 4 was used for potentiodynamic measurement; a schematic diagram of apparatus in three-electrode configuration is in Fig. 2. Scanning electron microscope JEOL JSM - 7000F was used for microscopic observations.

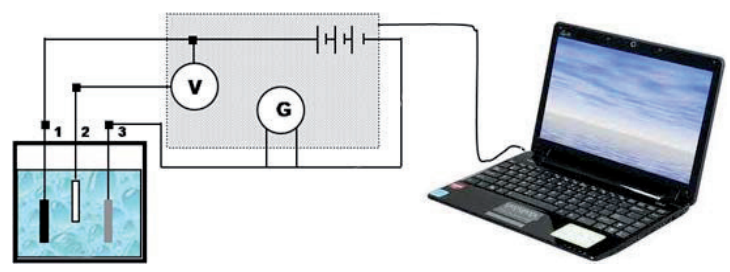

Fig. 2: Scheme of measurement of base corrosion characteristic with linear voltammetry method $V$ - voltmeter, $G$ - ammeter, 1 sample, 2 - SCE - saturated calomel electrode, 3 - Pt - auxiliary electrode.

\section{Results}

Fig. 3 shows that the force determining the strength of spot welds before their exposure to the corrosive environments was $\sim 11 \%$ higher in material $B$ in passivated state than in the case $A$ in nonpassivated state. Both materials were exposed to the corrosive environment of $5 \% \mathrm{NaCl}$ solution, after which increased carrying capacity of welds was observed in material B (passivated state). When the values of Fmax before and after the exposure to the corrosive environment are compared, strength increase was found in for both types of spot-welds (for samples A by $\pm 0.45 \%$, and samples $B$ by $\pm 5.1 \%$ ). Both materials were exposed to the corrosive environment of ecological solution Solmag, after which increased carrying capacity of welds was observed in material B (passivated state).

Fig. 4 shows the macrostructure of the cross- 
section of the weld. No signs of defects and, heat affected areas and local flashing of the $\mathrm{Zn}$ layer in the contact place of welding electrodes can be seen.

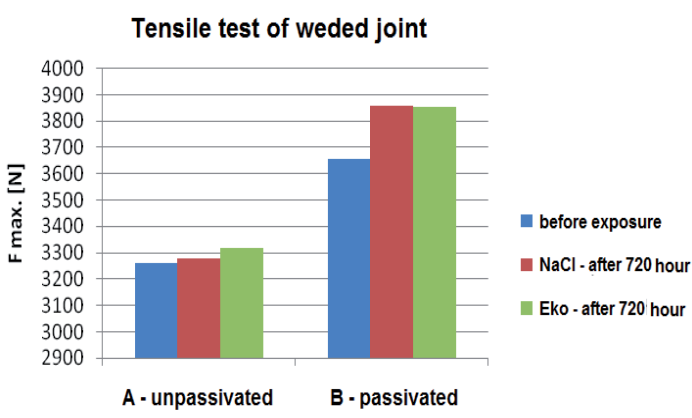

Fig. 3: Average values of maximum strength of $A$ and $B$ samples.

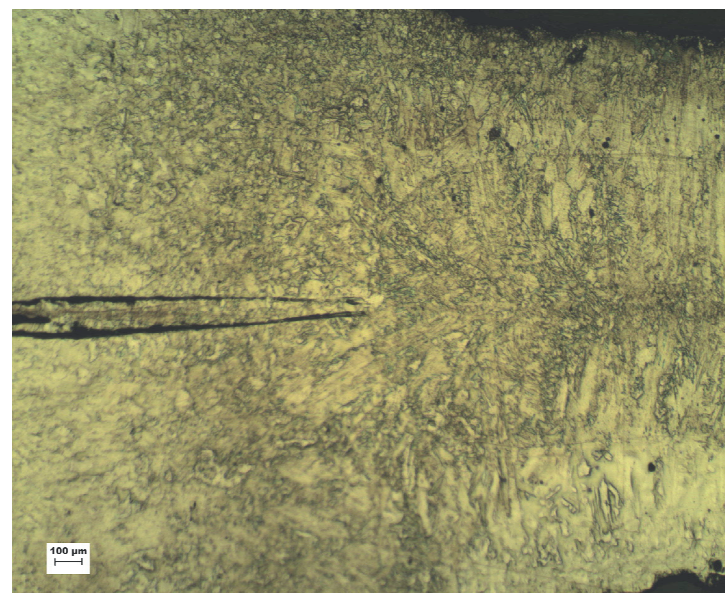

Fig. 4: Macrostructure of the cross section of the weld.

Fig. 5 illustrates the formation of the zinc corrosion products on the surface of the test samples after the corrosion tests in $\mathrm{NaCl}$ environments. It is possible to observe white zinc hydroxide, products of corrosion, which was confirmed by EDX analysis.

The measured values of microhardness are represented in Fig. 6. The measurements show that changes in parameters of resistance spot welding do not cause significant microhardness changes in the weld metal or heat affected zone of DX54D+Z steel.

Agresive environment does not influence microhardness of welds.

Galvanized sheet behaves like a galvanic cell when the moisture is present, where zinc layer with lower electric potential is the anode and steel rep- resents the cathode. Oxygen is very important factor in the atmospheric corrosion because the thin layers of moisture act as diffusion barriers into the condensed moisture $[8,9]$. Therefore, reaching the dew point is not necessary for the electrochemical reaction. As a result, very thin layer of electrolyte solution $(0.005$ to $0.15 \mathrm{~mm}$ ) forms on a metal surface already at a low humidity (corrosion humidity $\sim 60 \%)$.

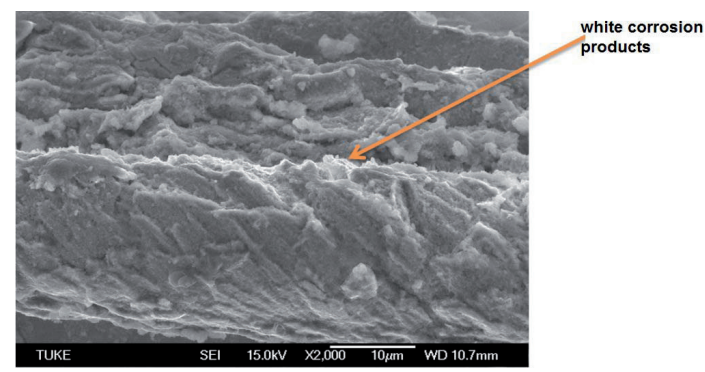

Fig. 5: Zinc layer on the sample surface after corrosion test

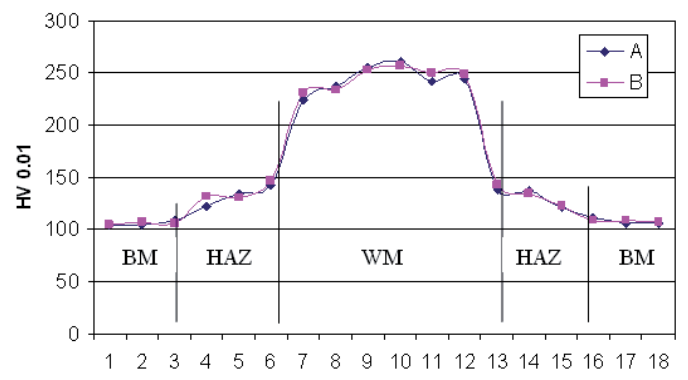

Fig. 6: Microhardness profile in materials A and B. BM - base material, HAZ - heat affected zone, WM - weld metal.

When the samples were exposed to the environment of $5 \% \mathrm{NaCl}$ solution for up to 240 hours, their weight increased due to formation of corrosion products, mainly zinc. However, when the exposure of samples to chloride environment exceeded 240 hours, there was a significant weight loss of zinc coating, caused by release of corrosion products into the electrolyte. The protective efficiency of zinc coating is significantly reduced in the aggressive environment. The comparison of weight losses of $A$ and $B$ samples in $5 \% \mathrm{NaCl}$ solution showed a difference of $53.66 \%$, Fig. 7 . It indicates that the passivated samples are more resistant to mass loss than non-passivated in $5 \% \mathrm{NaCl}$ solution. When the samples were exposed to the environ 
ment of the ecological solution Solmag, their weight did not significantly change during the time of exposure. The potentiodynamic polarization curves of the samples measured in both states (non-passivated and passivated surface) evaluated by Tafel method are shown in Fig. 8. Nonpassivated zinc-coated sheet (A) and passivated zinc-coated sheet (B) in $5 \% \mathrm{NaCl}$ solution after 720 hours exposure show the same corrosion current densities $J k$, i.e. passivation is effective only in the early phase of exposure.

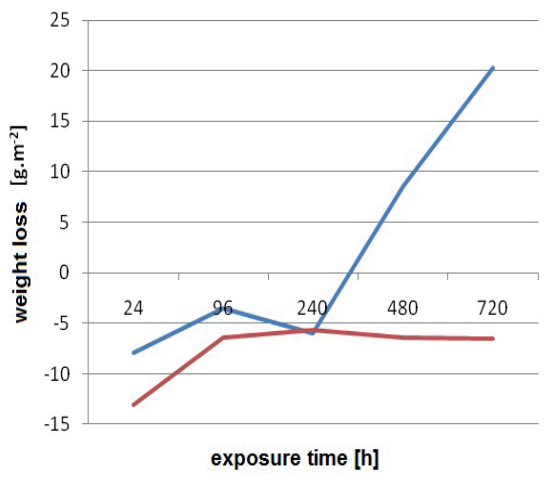

a)

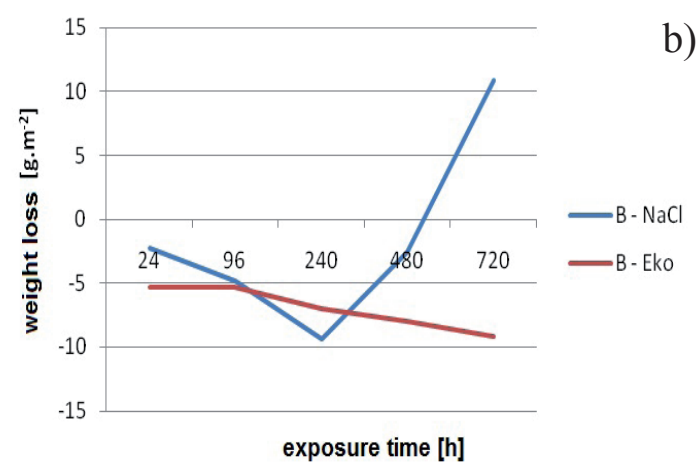

Fig. 7: Weight loss in corrosion enviroments, a) material $A$; b) material $B$.

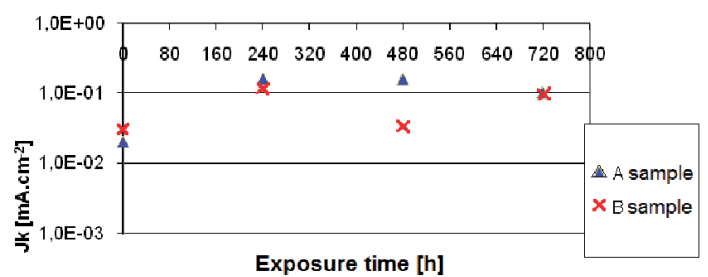

Fig. 8: Tafel method for determination of Jk.

The influence of chloride corrosive environment on galvanized sheets is so intense, that after sever- al tens of hours' exposure there is no significant difference between passivated and non-passivated surface in zinc-coated steel sheet.

An interesting phenomenon occured between 240 to 480 hours of passivated zinc-coated steel's exposure in non-aggressive environment, when the corrosion products show a high polarization resistance Rp to corrosion current flow (1.2 - 1.6 $\mathrm{M} \Omega$; see Fig. 9). However, after 720 hours of exposure, this passive layer is damaged even in lowaggressive environment and the "run-off" effect of zinc (emmissions of Zn into the environment) predominates.

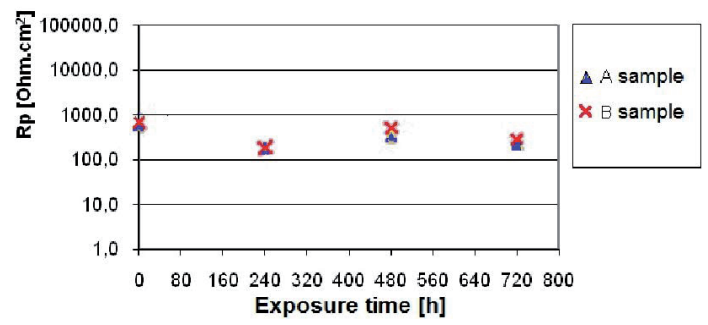

Fig. 9: Stern method for determination of $R p$.

\section{Conclusion}

Welds on passivated sheets have higher carrying capacity in their initial state than the welds on non-passivated sheets. After exposure of samples to both corrosive environments the welds on passivated samples have higher carrying capacity. This increase is caused by zinc corrosion products, which, despite their low adhesion to the substrate, increase the strength of welds.

The measured values of microhardness shown in Fig. 6 are in accordance with the observed microstructures and their components. The maximum values were measured in the sample in WM (261 HV $0,01)$. This value corresponds to microhardness of a dominant beintic compound in the weld metal. The change of microhardness in the weld metal was continuous and it corresponded to mixing the weld metal of particular types of steel.

Microscopic analysis proved high-quality of welds, which also showed that optimum technological parameters of welding were used. Local flashing of zinc layer was observed in the contact place of welding electrodes. After exposure of samples to corrosive environments, zinc corrosion products, so-called "white corrosion", formed, as a result of condensa- 
tion of air moisture or effect of the electrolyte.

The weight of samples exposed to ecological solution Solmag during corrosion tests increases in consequence of accrued zinc corrosion products, and the corrosion process is slower than when exposed to $\mathrm{NaCl}$ solution. In the relatively aggressive corrosive environment of $\mathrm{NaCl}$ there occurs significant weight loss. The potentiodynamic electrochemical measurements show that both types of sheets have the same corrosion current densities after 720 hours of exposure. That indicates that passivation is useful only in the early phase of exposure of materials to corrosive environment. Corrosion products with a high polarization resistance $\mathrm{Rp}$ form on the surface of the passivated samples, keeping their favorable properties up to approximately 500 hours of exposure to corrosive environment.

Optimization of spot resistance welding parameters is essential for improvement of the quality of the resulting joints as well as for minimization of technical risks, energy consumption and environmental impact.

\section{Acknowledge}

The paper is the result of the project implementation: Center for research of control of technical, environmental and human risks for permanent development of production and products in mechanical engineering (ITMS:26220120060) supported by the Research \& Development Operational Programme funded by the ERDF.

\section{References}

[1] Kaščák L., Spišák E., Joints of thin sheets made by forming and resistance spot welding: evaluations of properties, IDDRG 2007 - Forming the future, Györ, Mad’arsko, p. 545-550.

[2] Spišák E., Kaščák L'., Joining car body steel sheets using the clinching method, In: Acta Mechanica Slovaca, Vol. 15, No. 1, 2011, p. 28-34.

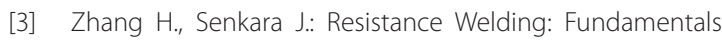
and Applications, Taylor\&Francis Group, New York, 2006.

[4] Tumuluru D. M.: The Effect of Coating on the Resistance Spot Welding Behavior of 780 MPa Dual-Phase Steel, Welding Journal, Vol. 86, 2007, No.9.

[5] Harlin N., Jones T.B., Parker J.D.: Weld Growth Mechanism of Resistance Spot Welds in Zinc Coated Steel, Journal of Materials Processing Technology, Vol. 143-144, 2003, p. 448453.

[6] Aslanlar S.:The effect of nucleus size on mechanical properties in electrical resistance spot welding of sheets used in automotive industry, Materials \& Design, Vol. 27, 2006, p. 125-131.

[7] Mabbutt S., Mills D., Woodcock Ch.: Developments of the electrochemical noise method (ENM) for more practical assessment of anti-corrosion coatings, Progress in Organic Coatings, Vol. 5, 2007, No. 3, p. 192-196.

[8] Chang B.H., Shi Y.W., Dong J.: A Study on the Role of Adhesives in Weld-Bonded Joints, Welding Research Supplement, 1999, p. 275-279.

[9] Stachowicz, F.: Instantaneous Plastic Flow Properties of Thin Brass Sheets Under Uniaxial and Biaxial Testing. In: Acta Mechanica Slovaca, Vol. 15, No. 1, 2011, p. 22-26.

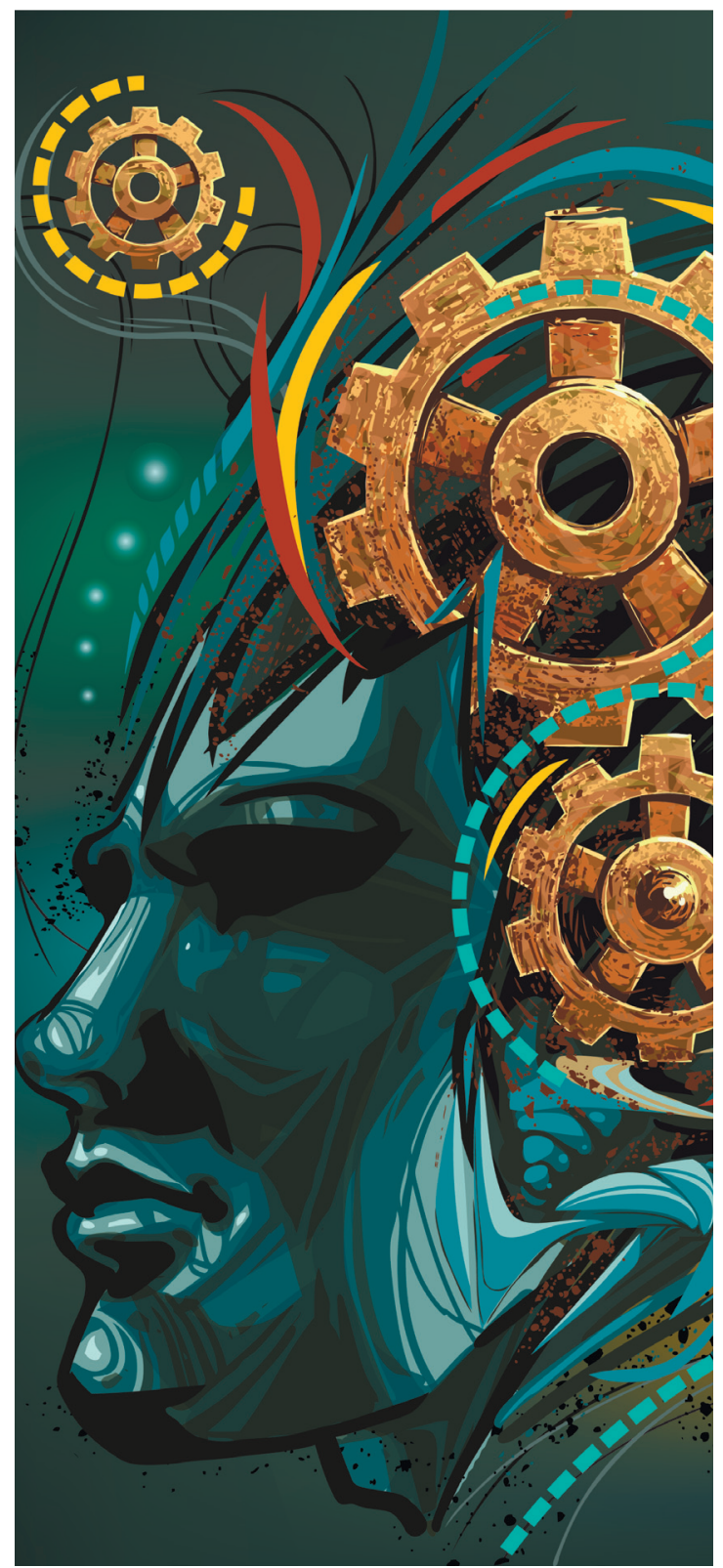

